International Journal of Biology, Pharmacy and Allied Sciences (IJBPAS) 'A Bridge Betusen caboratory and QRendor'

\author{
WwW.ijbpas.com
}

\title{
PHARMACEUTICAL MODIFICATION OF KAMADHUGHA RASA INTO A VALUE-ADDED SUSPENSION
}

\section{LEKSHMIPRIYA $S^{*}$, SARATH CHANDRAN C, DIVYA P}

1: Assistant Professor, Department of RSBK, Parul Institute of Ayurved, Parul University, Gujarat

2: Assistant Professor, College of Pharmaceutical Sciences, Government Medical College, Pariyaram, Kannur, Kerala

3: Associate Professor, Muniyal Institute of Medical Sciences, Manipal, Karnataka

*Corresponding Author: Dr. Lekshmipriya S; E Mali: ponni777@gmail.com

Received $9^{\text {th }}$ May 2021; Revised $10^{\text {th }}$ July 2021; Accepted $29^{\text {th }}$ Aug. 2021; Available online $15^{\text {th }}$ Dec. 2021

\section{https://doi.org/10.31032/IJBPAS/2021/10.12.1053}

\begin{abstract}
Recently the use of herbal medicines has increased all over the world due to their miraculous therapeutic effect and better safety profile. However, the delivery of drugs of natural origin may require modifications with the objective to achieve improved efficacy, to increase patient compliance, improved stability etc. Previously drugs of natural origin were not considered as agent to develop novel drug delivery system due to processing, standardizing, extracting and identification difficulties. But now a days with the advancement in formulation development, novel formulation technologies open the door towards the drugs of natural origin. This combination may result in the creation of new segment in health care. The present study aims to prepare a suspension which is a value-added formulation of Kamadhugha Rasa, a classical Ayurvedic formulation. The final product Kamadhugha Rasaisin powder form as per the classical references and it has to be administered to the patients along with the vehicles like ghee, honey etc. Soin order to make the formulation more user friendly it has been modified into a liquid dosage form. The liquid dosage form may provide better patient compliance for those with swallowing difficulties. There are potential advantages of oral liquid dosage forms, such as no dissolution time and rapid absorption from the stomach/intestines compared to solid dosage form. Considering these literary facts, liquid dosage form suspension was selected. Thus, sticking on to the basic principles by Acharya value addition was done in classical Kamadhugha Rasa form. While preparing suspension, instead of water amalaki swarasa was used. Artificial sucrose
\end{abstract}


was replaced by sugar mentioned as adjuvant in the formulation. The suspension was preserved by adding honey, a natural preservative. In addition to honey, Vitamin $\mathrm{C}$ in Amalaki also serves as a preservative. Thus, through the current study, a value- added suspension of Ayurvedic classical formulation Kamadhugha Rasa was developed and the analytical parameters were evaluated.

\section{Key words: Kamadhugha Rasa, Suspension, Value addition, Liquid dosage form}

\section{INTRODUCTION:}

Success of the treatment depends on the skillful preparation of the genuine drugs and their application against the disease condition. Hence the clinically excellent physician may stand superior to those who possess merely a theoretical knowledge of drugs.

A full conception of science will never be attained by the knowledge of only a part of science. (Ca. Vi. 7/4) While describing the qualities of an efficient physician, Charaka gives equal importance to practical training, clear grasp of theoretical knowledge, wide clinical experience, skill and purity of body as well as mind (Cha.Su.9/16-18). This also indicates towards the pharmaceutical proficiency of a Physician. Generally, Ayurvedic medicines (Aushadha) are the combinations of various drugs Selected on some rational basis and are manufactured under suitable pharmaceutical process in order to get not only their typical form i.e., Swarasa, Kalka, Churna, Kwatha, Avaleha, Sneha kalpana, Sandhana kalpana, etc. but also to modify as well as intensify their inherent properties.
Thus in nutshell, it may be stated that pharmaceutics, especially in the field of Ayurveda has one of the supreme importance. Because it includes all herboanimo-mineral preparations which need to processed by Sodhana, Marana etc. The study not only includes the drug manufacturing but also its dispensing to the patient in suitable form.

KAMADHUGHA RASA [1] mentioned in RASAYOGASAGARA is used in the treatment of Pandu. Considering the plausible incidence of anaemia in society; the ingredients are readily available and easily administered (Given as choorna mixed with honey, sugar and ghrita). The study aims to prepare a suspension which is a value-added formulation of kamadhugha rasa and to analytically evaluate the value-added formulation.

While preparing suspension, instead of water amalaki swarasa was used as vehicle. Artificial sucrose was replaced by sugar mentioned as 'anupana' (vehicle) in the classics. The presence of honey, a natural preservative may enhance the status of product without any reported side effects. 


\section{MATERIALS AND METHODS}

\subsection{Selection of Raw Materials}

The following were the raw materials used in the formulation after confirming the proper authenticity. The formulation Kamadhugha Rasa has been developed in Parassinikadavu Ayurveda Medical College, Kannur, Kerala.

Table 1: Raw Materials used for the preparation of Kamadhugha Rasa

\begin{tabular}{|c|c|c|c|}
\hline S. No. & Vernacular Name & Botanical name & Source \\
\hline $\mathbf{1}$ & Gairika & Iron oxide & Sulliya, Karnataka \\
\hline $\mathbf{2}$ & Amalaki & Emblica officinalis & Bonakkad Forest, Trivandrum \\
\hline $\mathbf{3}$ & Sitha & Saccharum officinarum & Thaliparamba, Kannur \\
\hline 4 & Madhu & Honey & Kutak, Ootty \\
\hline $\mathbf{5}$ & Ghritha & Ghee & Neyattinkara, Trivandrum \\
\hline
\end{tabular}

\subsection{Method of preparation of}

\section{Kamadhugha Rasa}

\section{a. Preparation of Kamadhugha Rasa:}

Purified Gairika (Ironoxide) was taken and triturated in freshly prepared Amalaki juice (Gooseberry) for seven times. The triturate was subjected for drying under direct sunlight to produce dry powder of Kamadhugha Rasa. b. Preparation of Sugar (Sitha) Base [2]: $66.7 \mathrm{~g}$ sugar was taken and dissolved in 100 $\mathrm{ml}$ distilled water under mild fire. It was boiled until syrup consistency was attained.

\subsection{Preparation of Kamadhugha Rasa}

\section{(K.D Rasa) Suspension:}

The suspension of Kamadhugha rasa was developed as per the composition given in

Table 2.

Table 2: Composition and formulation code for developed suspensions

\begin{tabular}{|c|c|c|c|c|c|}
\hline Formulation code & $\begin{array}{c}\text { Kamadhugha Rasa } \\
\text { (Drug) }\end{array}$ & Honey & $\begin{array}{c}\text { Sitha } \\
\text { powder }\end{array}$ & Sitha syrup & Amalaki juice \\
\hline F1 & $2.5 \mathrm{~g}$ & $10 \mathrm{ml}$ & $30 \mathrm{~g}$ & - & $60 \mathrm{ml}$ \\
\hline F2 & $2.5 \mathrm{~g}$ & $20 \mathrm{ml}$ & $30 \mathrm{~g}$ & - & $50 \mathrm{ml}$ \\
\hline F3 & $2.5 \mathrm{~g}$ & $10 \mathrm{ml}$ & $40 \mathrm{~g}$ & - & $50 \mathrm{ml}$ \\
\hline F4 & $2.5 \mathrm{~g}$ & $10 \mathrm{ml}$ & - & $40 \mathrm{ml}$ & $50 \mathrm{ml}$ \\
\hline F5 & $2.5 \mathrm{~g}$ & $10 \mathrm{ml}$ & - & $60 \mathrm{ml}$ & $30 \mathrm{ml}$ \\
\hline F6 & $2.5 \mathrm{~g}$ & $10 \mathrm{ml}$ & - & $30 \mathrm{ml}$ & $60 \mathrm{ml}$ \\
\hline
\end{tabular}

\subsection{METHOD OF PREPARATION:}

The prepared Kamadhugha Rasa powder was transferred to a dry motor. The powder was wetted using honey. Then syrup base was added to the motor and subjected to light trituration. Sufficient quantity of amalaki juice was added to transfer the preparation into a pourable consistency. The preparation was transferred into a calibrated measuring cylinder. The final volume was made up with sufficient quantity of amalaki juice. It should be shaken well and stored in an air tight bottle for further evaluation.

\subsection{Evaluation of Oral Suspension}

\section{Formulations:}

Developed formulations were evaluated on the basis of following parameters,

- Physicalevaluation

- $\mathrm{pH}$ 
- Redispersibility

- SedimentationVolume

\section{Physical evaluation}

Color, appearance, taste and odor for all the developed suspensions were performed and reported.

2. $\mathbf{p H}$

The $\mathrm{pH}$ values of suspensions were measured by digital $\mathrm{pH}$ meter, which was calibrated using buffer of $\mathrm{pH} 4$ and pH7. The electrodes were completely dipped in the formulations and $\mathrm{pH}$ was noted.

\section{Redispersibility}

Bottles containing suspension was held upright between the fingers and rotated clock wise upside down through $180^{\circ}$ in a semi-circle path and back in the anti-clock direction. This process was repeated continuously until the sediment was completely redispersed. Number of such cycles for complete redispersibility was noted.

\section{Sedimentation volume}

$50 \mathrm{ml}$ of developed suspension was taken in a calibrated $100 \mathrm{ml}$ measuring cylinder. The sample was shaken well and kept aside. The initial volume of suspension was noted at ' 0 ' minutes and denoted as $V_{0}$. The volume of sediment was measured at fixed time intervals $(\mathrm{Vu})$. The Sedimentation volume was calculated using following equation:
Sedimentation volume, $\mathbf{V S}=\mathbf{V u} \div \mathbf{V O}$

VU - volume of sediment was measured at fixed time intervals

VO -Initial volume of suspension

\subsection{Selection of best formulation}

Based on selected parameters such as physical evaluations, $\mathrm{pH}$, redispersibility and sedimentation volume, the best developed formulation may be selected and was subjected for further evaluation.

\subsection{Evaluation of best formulation}

Selected best formulation was evaluated on the basis of following parameters,

- Flow rate

- Viscosity

- Stability studies

\section{$1 \quad$ Flow rate}

The time required for each suspension sample to flow through a $10 \mathrm{ml}$ graduated pipette may be measured.

Flow rate $=$ Volume of pipette $(\mathrm{ml}) \div$ Flow rate $($ in sec $)$

\section{Viscosity}

The viscosity of developed suspensions was determined by using Brookfield viscometer LVDV- Prime I with a small volume adaptor (Fig. No.01). The viscosity was recorded at varying RPM and torque. 


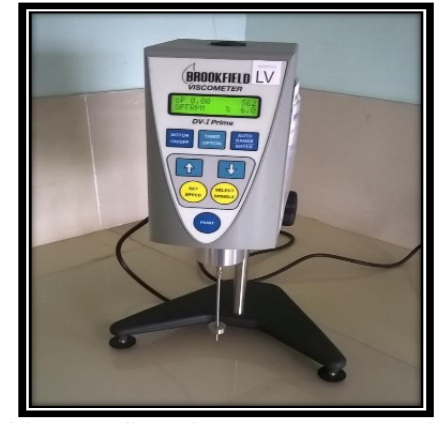

Fig. No. 01 Brookfieldviscometer LVDVPrime I with spindle

3. Stability studies

Stability studies of developed formulation were carried out using ICH guideline for accelerated testing with required modifications. All the developed formulations were selected and filled into the collapsible tubes and stored at temperature of $42^{\circ} \mathrm{C}, \quad 30 \pm 2^{\circ} \mathrm{C} \quad$ and $45 \pm 2^{\circ} \mathrm{C}$ RH for a period of 45 days. After the period of 45 days, samples were tested for physical characteristics, $\mathrm{pH}$, color, consistency and particle size.

\section{RESULTS \&DISCUSSION:}

\subsection{Evaluation of developed suspensions}

Out of various liquid dosage forms, suspensions are becoming more popular due to its ease of administration and better absorption. Oral Suspension is comparatively easier to prepare and touse [3] (Brionetal., 2003). It has been stated that the suspensions were a very useful dosage forms for insoluble or poorly water-soluble drugs for oral administration [4] (Ashford, 2007). However, the physical, chemical and microbiological stability may be a major obstacle for the dosage form. To ensure the quality of product, all the developed suspension formulations were subjected for evaluation tests such as physical evaluation by organoleptic characters, $\mathrm{pH}$, redispersibility and sedimentation volume. Based upon these evaluation parameters, the best formulation may be selected and subjected for further evaluationtests.

\section{Physical evaluation}

The developed suspension formulations were subjected for physical characterization such as color, taste, odor and nature (Table No. 03). All the developed suspension formulations were brown in color, which may be due to the influence of color of the kamadhugha rasa and drug interaction with amalaki juice. All the samples were tested for gestation after proper cleansing of mouth. Among the samples, F1 \& F3 were nonpalatable due to its increased sweetish taste. All other samples were agreeable in palatability. Nature and odor of all formulations were liquid and amla specific respectively.

\section{2. $\quad$ pH of developed suspensions}

The $\mathrm{pH}$ for all the developed suspension formulations were between $3.0-$ 3.2, which were within the acceptable limit (Table No. 04). The $\mathrm{pH}$ measured for the developed suspension formulations makes it safer and suitable for the daily administration. The addition of amalaki juice in the formulation was able to manage the 
$\mathrm{pH}$ within the acceptable limits. An acidic

$\mathrm{pH}$ is well suited for the systemic absorption of Iron; hence developed formulations may enhance iron absorption in body due to its acceptable pHvalue.

\section{Redispersibility of developed suspensions}

As per the literature review the ideal suspension must be capable of re-dispersion with a minimum effort [5]. Among the developed formulations, F1 and F3 showed poor redispersibility, F2 showed average redispersion in comparison with F4-F6 formulations (Table No. 04).

\section{Sedimentation volume}

Sedimentation volume was determined by keeping a measured volume of suspension in a graduated cylinder in an undisturbed state for sixty minutes and noted the volume of the sediment which is expressed as ultimate height. Remington's pharmaceutical science discusses the attributes of an acceptable suspension. There are certain criteria that a well formulated suspension should meet; the disperse particles should be of such a size that they do not settle rapidly in the container. In the event that sedimentation occurs, the sediment must not form a hardcake (Table No. 5).

Based on the sedimentation volume, the formulations F4, F5 and F6 showed more or less same sedimentation volume. Among them F6 showed highest sedimentation
Volume

Based on parameters evaluated during investigation, Formulation F6 may be suggested as the best as well as optimized formulation, hence formulation F6 may be recommended for further evaluation studies to establish its properties as a stable as well as effective oral suspension containing Kamadhugha Rasa was selected as the best and subjected for further evaluations. All the evaluations were repeated thrice and average values were taken.

\section{Flow rate}

An ideal suspension should be easy to pour and pleasant to consume. The flow rate of the developed suspension formulation was $2.5 \mathrm{ml} / \mathrm{sec}$ (Table No. 06), which may be convenient for the user, while transferring the product during usage, which highlights its optimized flow rate.

\section{Viscosity}

Viscosity for developed suspension formulation was measured using Brookfield viscometer LVDV-Prime IthespindleNo.S64 was selected on trial-and-error basis. The viscometer was operated at 10, 20, 50 and $100 \mathrm{rpm}$ and the torque were observed between $60-70 \%$ (Table No. 07).

Determination of viscosity was an important parameter during the evaluation of suspension formulations. The viscosity for the developed suspension formulations may influence sedimentation volume and effective release of active ingredient from 
the formulation. Hence the optimized viscosity may be preferred during the development of suspension formulation.

During the measurement of viscosity, as the rpm was increased from 10 to 100 , its viscosity was found to be decreasing. The reduction in viscosity with increase in rpm shows the rheological property of a pseudo-plastic system, hence the formulation F6 may be considered as a good liquid dosage form with better rheological properties.

\section{Stability studies}

It is essential to maintain the stability of developed formulations over the period of its shelf life. The developed suspension formulation F6 was subjected to accelerated stability studies for a period of 45 days. Accelerated stability studies were performed in accordance with ICH guidelines with required modifications. The samples of F6 were maintained at $4 \pm 2^{\circ} \mathrm{C}, 30 \pm 2^{\circ} \mathrm{Cand} 45 \pm 2{ }^{\circ} \mathrm{C}$ for a period of 45 days. The change in colour, consistency, $\mathrm{pH}$ and particle size were monitored for a period of 45 days and reported. The results of the study were summarized in Table No.08.

Table No.03: Organoleptic features of developed suspensions

\begin{tabular}{|c|c|c|c|c|}
\hline Formulation & Color & Taste & Odor & Nature \\
\hline F1 & $\begin{array}{c}\text { Pale } \\
\text { Brown }\end{array}$ & Highly Sweet & $\begin{array}{c}\text { Amla } \\
\text { specific }\end{array}$ & Liquid \\
\hline F2 & $\begin{array}{c}\text { Pale } \\
\text { Brown }\end{array}$ & $\begin{array}{c}\text { Moderately } \\
\text { Sweet }\end{array}$ & $\begin{array}{c}\text { Amla } \\
\text { specific }\end{array}$ & Liquid \\
\hline F3 & Brown & Highly Sweet & $\begin{array}{c}\text { Amla } \\
\text { specific }\end{array}$ & Liquid \\
\hline F4 & Brown & Sweetish sour & $\begin{array}{c}\text { Amla } \\
\text { specific }\end{array}$ & Liquid \\
\hline F5 & Brown & Sweetish sour & $\begin{array}{c}\text { Amla } \\
\text { specific }\end{array}$ & Liquid \\
\hline F6 & Brown & Moderate sweetish sour & Amla specific & Liquid \\
\hline
\end{tabular}

Table No.04: pH and Redispersibility of developed suspensions

\begin{tabular}{|c|c|c|}
\hline Formulation & $\mathbf{p H}$ & $\begin{array}{r}\text { Redispersibility } \\
\text { (No. of cycles) }\end{array}$ \\
\hline F1 & 3.1 & 4 \\
\hline F2 & 3.0 & 3 \\
\hline F3 & 3.2 & 4 \\
\hline F4 & 3.3 & 2 \\
\hline F5 & 3.1 & 2 \\
\hline F6 & 3.0 & 2 \\
\hline
\end{tabular}

Table No.05: Sedimentation volume of suspensions

\begin{tabular}{|c|c|c|c|c|c|c|c|c|c|c|c|c|c|c|}
\hline \multirow[t]{2}{*}{ SI No } & \multirow{2}{*}{$\begin{array}{c}\text { Time } \\
(\min ) \mathrm{T}\end{array}$} & \multirow[b]{2}{*}{ Vo } & \multicolumn{2}{|c|}{ F1 } & \multicolumn{2}{|c|}{ F2 } & \multicolumn{2}{|c|}{ F3 } & \multicolumn{2}{|c|}{ F4 } & \multicolumn{2}{|c|}{ F5 } & \multicolumn{2}{|c|}{ F6 } \\
\hline & & & $\mathbf{V U}$ & VS & $\mathbf{V U}$ & VS & $\mathbf{V U}$ & VS & $\mathbf{V U}$ & VS & $\mathbf{V U}$ & VS & $\mathbf{V U}$ & $\mathrm{VS}$ \\
\hline 1 & 0 & 50 & 50 & 1 & 50 & 1 & 50 & 50 & 50 & 1 & 50 & 1 & 50 & 1 \\
\hline 2 & 10 & 50 & 48 & .96 & 48 & .96 & 47 & .94 & 46 & .92 & 45 & .90 & 47 & .94 \\
\hline 3 & 20 & 50 & 45 & .90 & 46 & .92 & 45 & .90 & 40 & .80 & 44 & .88 & 35 & .70 \\
\hline 4 & 30 & 50 & 31 & .62 & 30 & .60 & 31 & .62 & 18 & .36 & 24 & .48 & 22 & .44 \\
\hline 5 & 40 & 50 & 21 & .42 & 20 & .40 & 21 & .42 & 15 & .30 & 21 & .42 & 20 & .40 \\
\hline 6 & 50 & 50 & 18 & .36 & 18 & .36 & 19 & .38 & 15 & .30 & 20 & .40 & 18 & .36 \\
\hline 7 & 60 & 50 & 17 & .34 & 17 & .34 & 18 & .36 & 14 & .28 & 19 & .38 & 17 & .34 \\
\hline
\end{tabular}




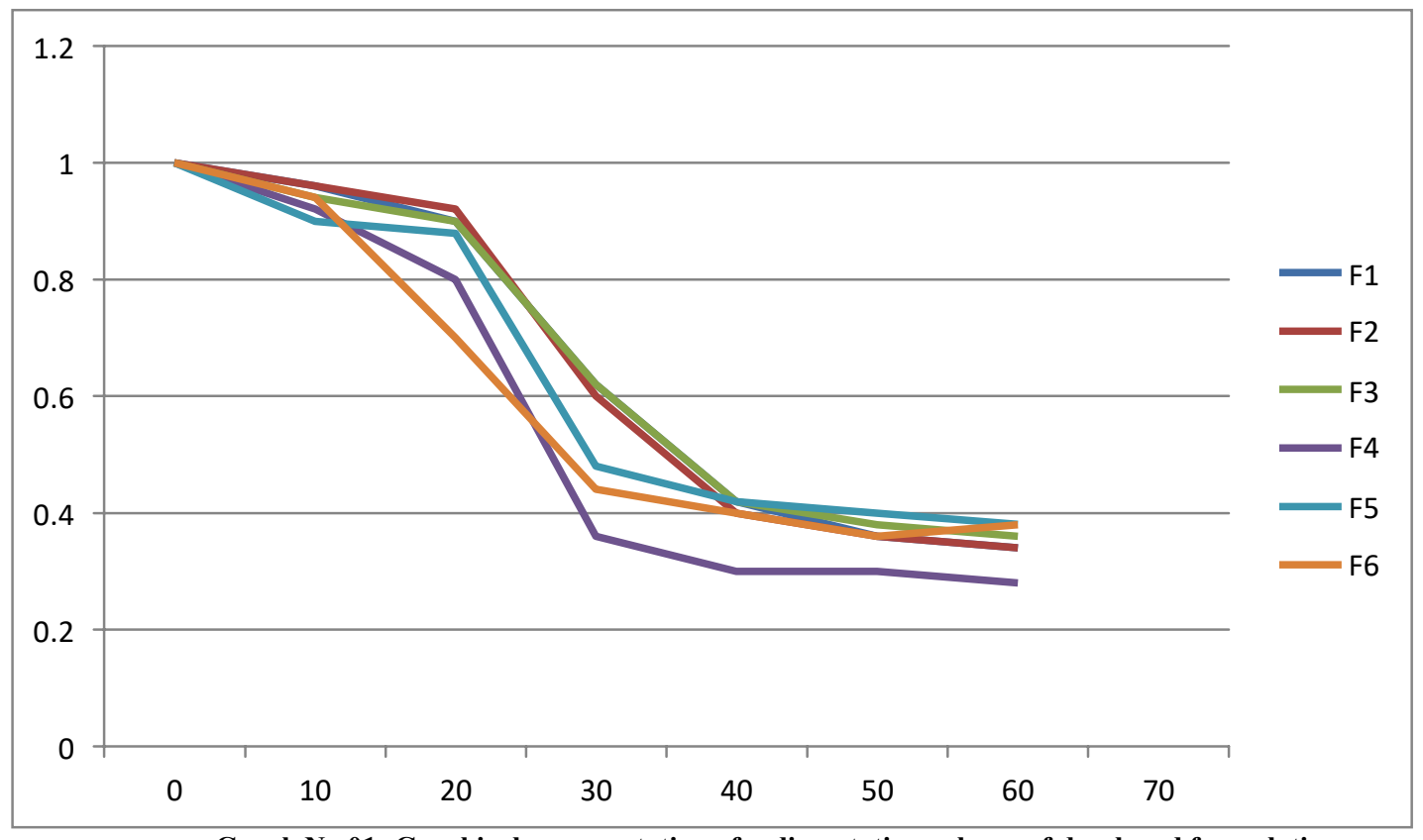

Graph No.01: Graphical representation of sedimentation volume of developed formulations

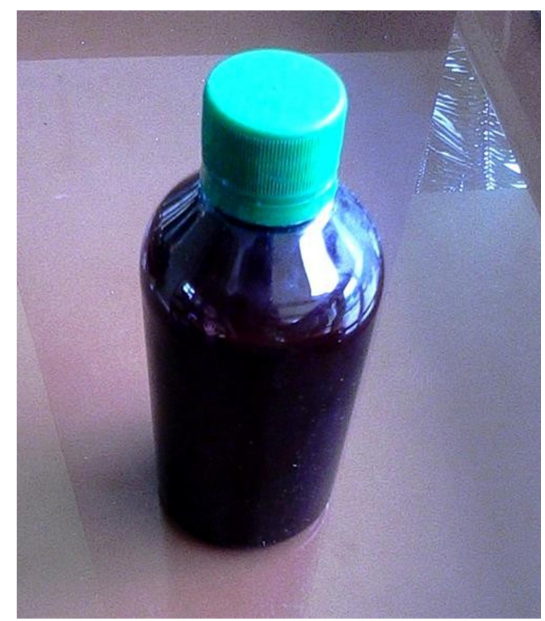

Fig No.02: Formulation F6

Table No. 06: Flow rate of developed suspension formulation F6

\begin{tabular}{|c|c|c|c|c|}
\hline Formulation & Volume & Time taken & Flow rate & Observation \\
\hline F6 & $10 \mathrm{ml}$ & $4 \mathrm{sec}$ & $2.5 \mathrm{ml} / \mathrm{sec}$ & Easy and uniform \\
\hline
\end{tabular}

Table No.07: Viscosity of developed formulation F6

\begin{tabular}{|c|c|c|}
\hline Sl. No & RPM & Viscosity(cps)* $^{*}$ \\
\hline 1 & 10 & $\mathbf{1 2 0 . 6} \pm 0.021$ \\
\hline 2 & 20 & $70.5 \pm 0.032$ \\
\hline 3 & 50 & $40.8 \pm 0.023$ \\
\hline 4 & 100 & $33.6 \pm 0.012$ \\
\hline
\end{tabular}

*Sampling in triplicate 


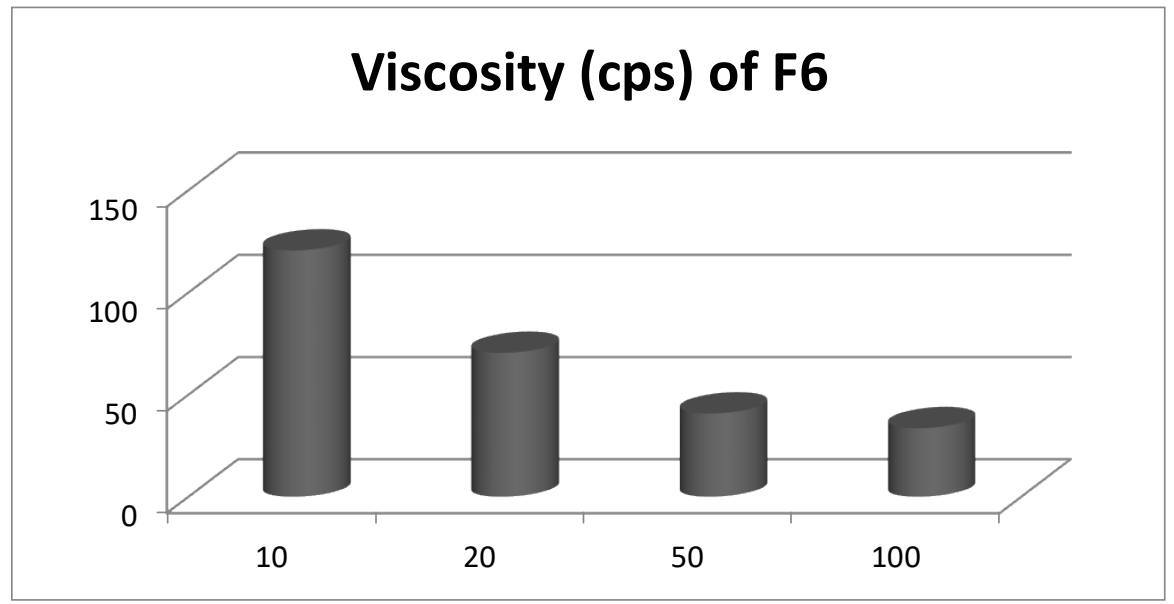

Graph No.02: Viscosity of developed formulations

Table No.08: Stability study data for formulation F6

\begin{tabular}{|c|c|c|c|c|c|c|c|c|}
\hline \multirow{3}{*}{ Temperature } & \multicolumn{8}{|c|}{ Evaluation parameters } \\
\hline & \multicolumn{2}{|c|}{ Color } & \multicolumn{2}{|c|}{ Consistency } & \multicolumn{2}{|c|}{ pH } & \multicolumn{2}{|c|}{ *Particle size } \\
\hline & Initial & Final & Initial & Final & Initial & Final & Initial & Final \\
\hline$\left(4 \pm 2^{\circ} \mathrm{C}\right)$ & Brown & Brown & liquid & liquid & 3.0 & 3.0 & $12.4 \mu \mathrm{m}$ & $12.4 \mu \mathrm{m}$ \\
\hline$\left(30 \pm 2^{\circ} \mathrm{C}\right)$ & Brown & Brown & liquid & liquid & 3.0 & 3.0 & $12.4 \mu \mathrm{m}$ & $12.4 \mu \mathrm{m}$ \\
\hline$\left(45 \pm 2^{\circ} \mathrm{C}\right)$ & Brown & Brown & liquid & liquid & 3.0 & 3.0 & $12.4 \mu \mathrm{m}$ & $12.4 \mu \mathrm{m}$ \\
\hline
\end{tabular}

*Particle size calculated by length mean diameter

There was no significant change observed with any of the selected parameters during the stability study period of 45 days. This confirmed the good stability profile of developed suspension formulation. The good manufacturing practices and the presence of ingredients in optimized quantity might have contributed for better stability of product. The stability study suggested that, developed product may remain stable at temperature condition of $4 \pm 2^{\circ} \mathrm{C}$ to $45 \pm 2^{\circ} \mathrm{C}$.

\section{CONCLUSION:}

Novel formulation development technologies have gained the importance due to their ability to achieve modified delivery of drugs of natural origin thereby improving the therapeutic value as well as reducing toxicity. These modern formulations were successful in delivering the incorporated herbal drug at predetermined rate at the site of action and increase the bioavailability of the drugs. The formulations with herbal or natural constituents minimize the drug degradation or pre systemic metabolism and serious side effects by accumulation of drugs to the non-targeted area. This results in improved safety profile of the medicines especially when used in the pediatrics and geriatric patients $[5,6]$. Value addition is are lative proposition assuming magnanimous importance in today's dynamic world. The enhancement of value of a product by the addition of any factor to it is known as value addition. In general, adding value is the process of state of changing or transforming a 
product from its original state to a more valuable. Thus, value added modification as suspension of Kamadhugha Rasa has been formulated. The Kamadhugha Rasa suspension was designed without adding any artificial ingredients like suspending agents, preservatives etc. A Natural Ayurvedic Suspension was well formulated with amalaki swarasa as base instead of water, sitha instead of artificial sucrose and honey as a natural preservative. Also, Vitamin C present in amalaki also serves as a natural preservative.

\section{REFERENCES:}

[1] Vaidya Hariprapanna Sharma, Rasayogasagaram, ISBN81-2180005-6(VOL.1), Chowkamba Sanskrit series, Varanasi, page no.260, slokano.702-705

[2] Mithal BM. The text book of pharmaceutical formulation. Vallabh Prakasan, Delhi, 1980,170177.

[3] Brion F, Nunn AJ, Rieutord A: Extemporaneous (magistral) preparation of oral medicines for children in European hospitals. Acta Paediatr 92: 486-490,2003.

[4] Ashford M: Bioavailability physicochemical and dosage form factors. In:Aulton'sPharmaceutics, The design and manufacture of medicines, p. 286-303, 3rd ed. Ed.
Aulton ME, Churchill Livingstone Elsevier, Hungary2007

[5] Jerry ethnghuysen R. Ph, Gary garlson $\mathrm{R} \mathrm{PhD} \mathrm{Preparation} \mathrm{of} \mathrm{oral}$ suspensions and syrups: basic concepts, new product development pharmacist paddock laboratories university of munnesto, college of pharmacy.vol2/page1

[6] Ashwani Goyal, Sandeep Kumar, Manja Nagpal, Inderbir Singh, Sandeep

Arora.PotentialofnovelDrugDeliver ySystemforHerbalDrugs.Ind.JPharm EduRes 2011;45(3)225-235

[7] Kulkarni Giriraj T. Herbal Drug Delivery system: An emerging area in Herbal Drug Research. J Chr D D 2011;2(3):113-119. 
KAMADHUGHA RASA-SUSPENSION PREPARATION

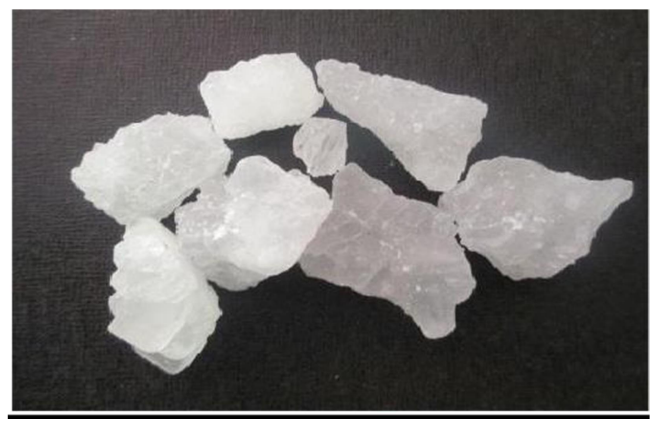

Fig no: 1 Sitha

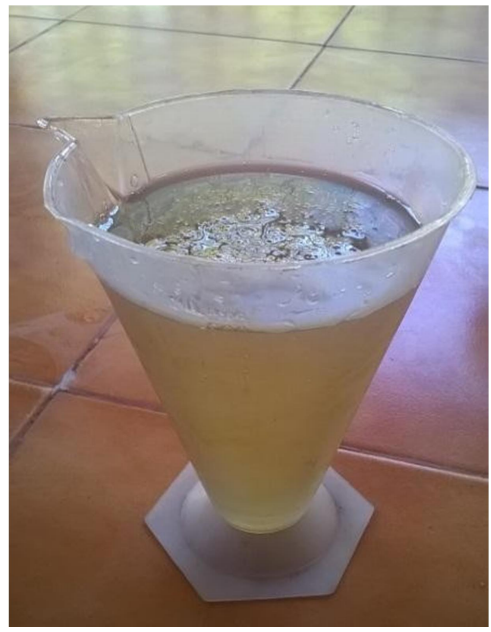

Fig no. 3: Sitha syrup

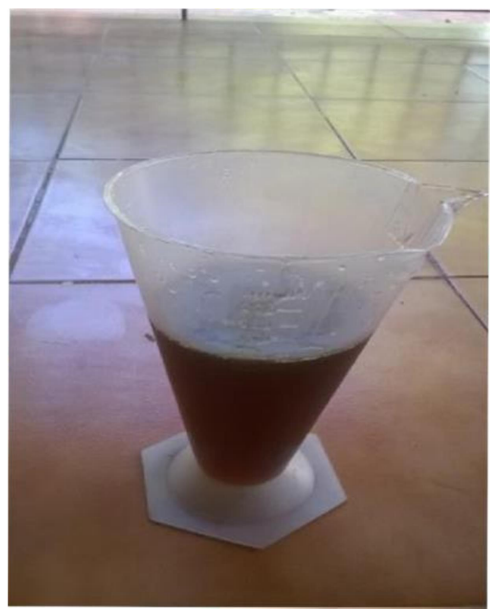

Fig no. 5: Honey

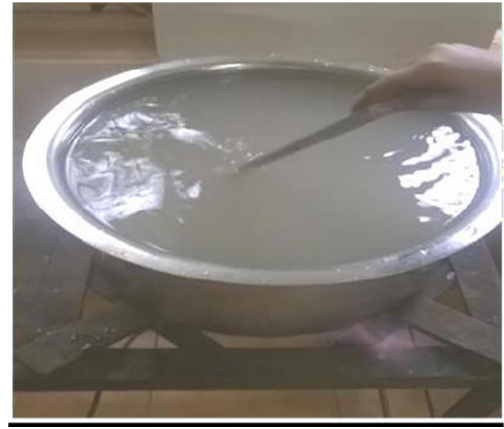

Fig no: 2 Preparation of Sitha syrup

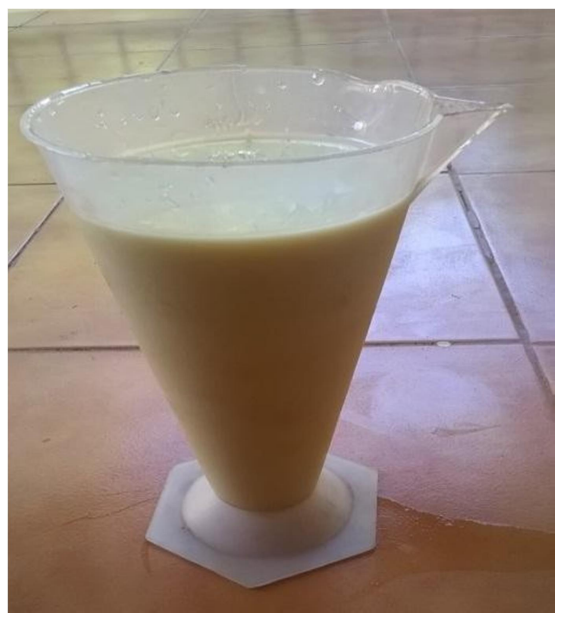

Fig no 4: Amalaki swarasa

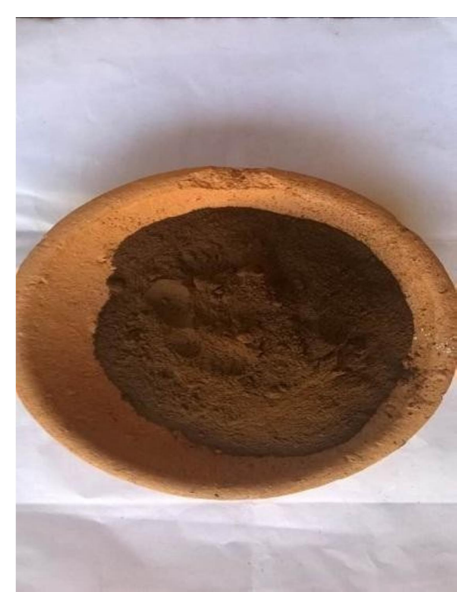

Fig no.6 : Kamadhugha Rasa 


\section{METHOD OF PREPARATION}

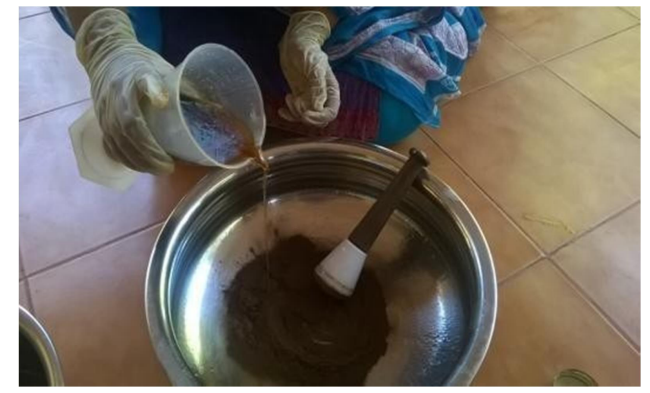

Fig no.1: Mixing of Drug and Honey

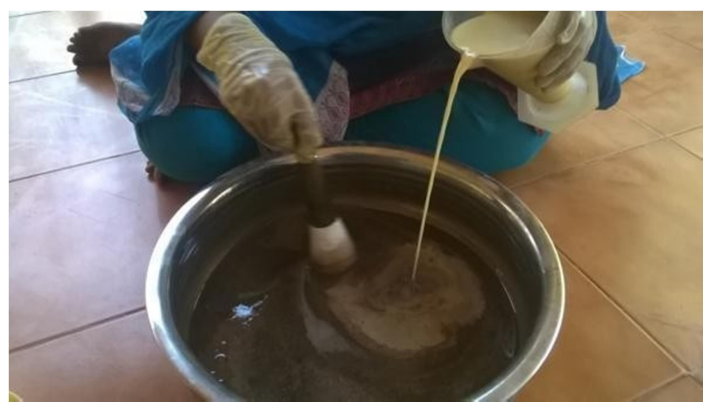

Fig no.3 Adding of Amalaki Swarasa

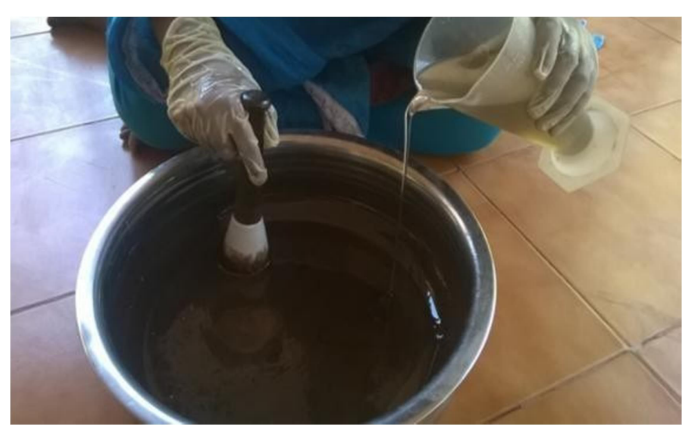

Fig no. 2: Adding of Sitha syrup

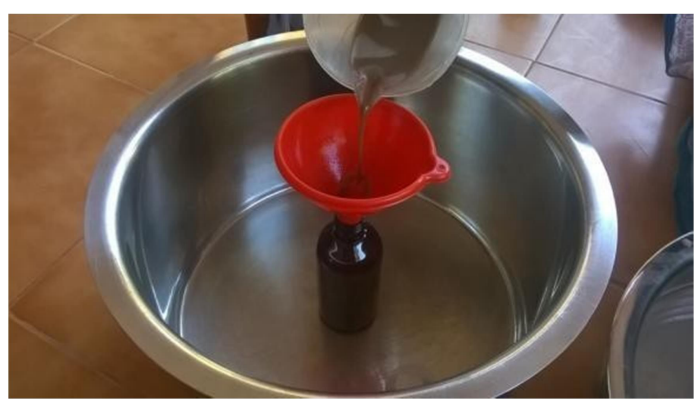

Fig no. 4: Filling in bottles

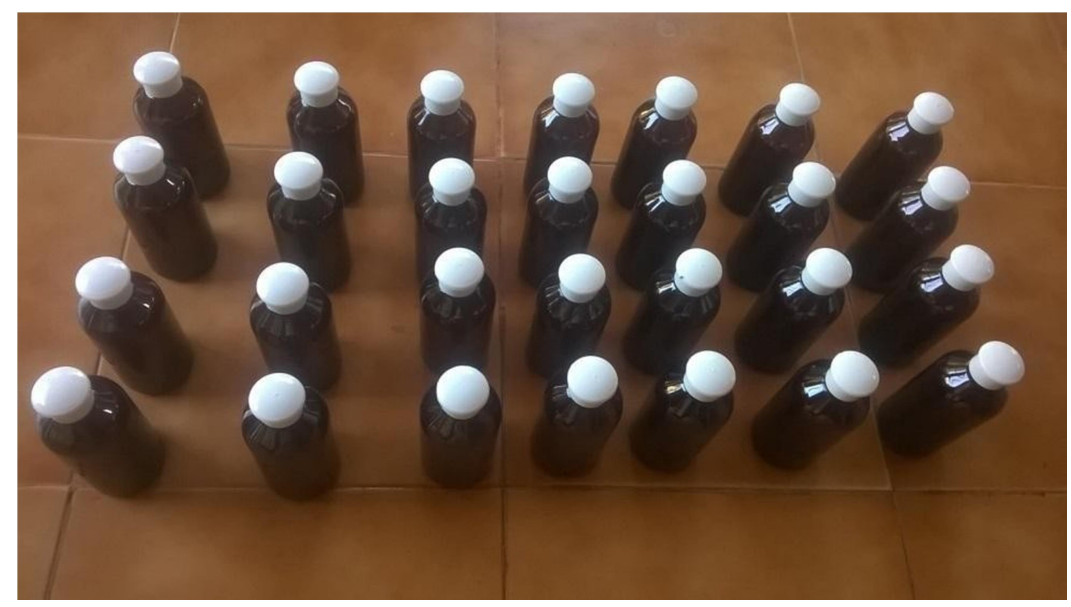

Fig no. 5: Packed bottles for dispensing 